\title{
A video clip of the biting midge Culicoides anophelis ingesting blood from an engorged Anopheles mosquito in Hainan, China
}

\author{
Yajun $\mathrm{Ma}^{1 *}$, Jiannong $\mathrm{Xu}^{2^{*}}$, Zhenzhou Yang ${ }^{3 *}$, Xiaohua Wang ${ }^{4}$, Zhongling Lin ${ }^{4}$, Wei Zhao ${ }^{5}$, Yan Wang ${ }^{1}$, \\ Xiangyu $\mathrm{Li}^{1}$ and Hua Shi ${ }^{3}$
}

\begin{abstract}
Background: Biting midges are hematophagus ectoparasites of insects, humans and other animals. Culicoides (Trithicoides) anophelis Edwards1922 is a predator of engorged mosquitoes.

Findings: In a field trip of wild mosquito collections, C. anophelis was found on two Anopheles mosquitoes. One mosquito with a midge clinging onto its abdomen was caught on video demonstrating the act of the midge taking blood from the engorged mosquito Anopheles vagus. The midge C. anophelis has a broad host range. Documented in the literature, the midge has been found in various mosquito species in the genera Anopheles, Culex, Aedes and Armigeres.

Conclusions: A video clip was presented demonstrating a midge taking blood from an engorged mosquito. The host promiscuity of $C$. anophelis raises a concern about its potential as a mechanic or biological vector to spread viruses among mosquito populations.
\end{abstract}

Keywords: Culicoides anophelis, Anopheles mosquito, Biting midge, Video

\section{Findings}

The biting midge Culicoides (Trithecoides) anophelis Edwards is a predator of engorged mosquitoes, which was first described by Edwards in 1922 [1]. Later in 1947, Liard reported a C. anophelis sucking engorged blood from the abdomen of a flying mosquito Armigeres lacuum [2]. In the 1950s, C. anophelis was found on the mosquitoes in the genera Aedes, Anopheles, Armigeres and Culex mosquitoes in Hainan, China [3]. There are several reports of the midge in India [4,5]. Here we report two anopheline mosquitoes that were attacked by C. anophelis, and one scene was caught on video demonstrating the act of a midge taking blood from an engorged mosquito.

\footnotetext{
*Correspondence: yajun_ma@163.com; jxu@nmsu.edu;

pcochina@hotmail.com

'Department of Tropical Infectious Diseases, Second Military Medical

University, 800 Xiangyin Road, 200433 Shanghai, China

${ }^{2}$ Department of Biology, New Mexico State University, PO Box 30001 MSC

3AF, Las Cruces, NM 88003, USA

Full list of author information is available at the end of the article
}

The observation was made in the course of a mosquito collection on the evening of August 10, 2013 in Yanfeng, Haikou, Hainan Province, China. Mosquitoes were attracted and trapped in a net trap inside which a cow was placed. The trapped mosquitoes were caught by an electronic aspirator and released into a cage and brought back to the laboratory for further processing. When sorting out mosquitoes, one mosquito was found to have a midge clinging to its abdomen (Figure 1). The mosquito was identified as Anopheles sinensis and the midge was identified as $C$. anophelis. The next day, another mosquito collection was carried out using the same baited trap. Among the mosquitoes collected, another mosquito was found carrying a midge. The mosquito and midge were chloroformed lightly, the mosquito was immobilised and the midge was active and hanging onto the mosquito abdomen. The mosquito and midge were placed under a stereo microscope (Nickon SMZ745T). A video was recorded with a camera (Additional file 1). On the video footage, the midge firmly attached itself to the mosquito via the mouthparts that had penetrated the 


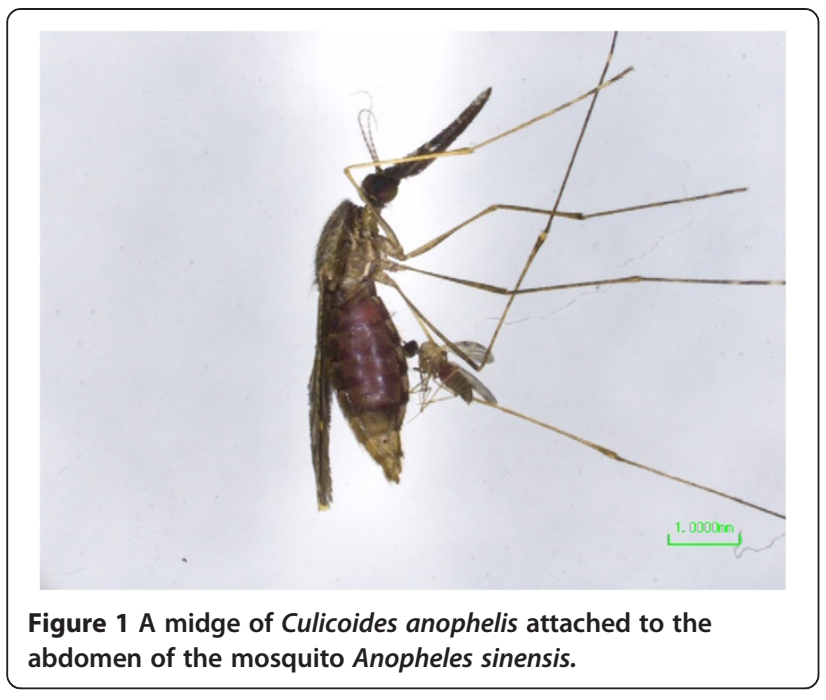

lateral part of the fourth segment of the engorged abdomen. The midge abdomen distended with blood in it. Periodically the legs were moving agitatedly. About $3 \mathrm{mi}-$ nutes later, the midge was trying to remove its mouthparts from the mosquito. It appeared difficult to unplug the proboscis, the midge rotated $180^{\circ}$ with the mouthparts inside the abdomen and finally detached from the mosquito. The steady attachment may be attributed to the structure of the mouthparts [6,7], which ensures that midges can hang onto flying mosquitoes while ingesting blood. Documented by Edwards (1922) and Chhila and Chaudhry (2010), the midge could remain attached to its host mosquito for $48-56 \mathrm{hr}[1,4]$. The mosquito was identified as $A n$. vagus, and the midge was identified as C. anophelis by morphology [1].

At least 19 mosquito species in the genera Anopheles, Culex, Aedes and Armigeres have been documented as hosts of $C$. anophelis (Table 1). These data indicate that $C$. anophelis has a broad host range. Furthermore, the infestation is commonly seen in the mosquito specimens in field collections [1-3]. In a recent report the midges were found on 8 of $11(72.7 \%)$ An. stephensi collected in cattle sheds in India [4]. In another report from India, the prevalence of C. anophelis was 6.7\% (87/1297) in five midge collections from April to August in 2004 [5]. Interestingly, in the same report, some of $C$. anophelis were caught directly on cattle and buffaloes, which indicates that $C$. anophelis can feed on animals other than mosquitoes [5]. Certain mosquitoes and Culicoides midges are vectors for arboviruses that cause human and/or animal diseases, such as mosquito-borne Dengue virus, West Nile virus, Japanese encephalitis virus, and midge-borne bluetongue virus, Oropouche virus and Schmallenberg virus [8-10]. The fact that $C$. anophelis takes blood from a broad range of mosquitoes raised a concern that the midge may serve as a mechanism for biological vectors to spread viruses among
Table 1 Mosquito species known to be infested by $C$. anophelis

\begin{tabular}{lc}
\hline Mosquito species & Reference \\
\hline Aedes vexans & 3 \\
Anopheles aconitus & 1 \\
Anopheles annularis & 2 \\
Anopheles fuliginosus & 1 \\
Anopheles hyrcanus & 1 \\
Anopheles karwari & 1,2 \\
Anopheles maculatus & 2 \\
Anopheles maculipennis & 2 \\
Anopheles nigerrimus & 2 \\
Anopheles sinensis & 2,3, current \\
Anopheles stephensi & 4 \\
Anopheles umbrosus & 1 \\
Anopheles vagus & $1,2,3$, current \\
Armigeres lacuum & 2 \\
Armigere sobturbans & 3 \\
Culex bitaeniorhynchus & 3 \\
Culex fatigans & 3 \\
Culex tritaeniorhynchus & 3 \\
Culex whitmorei & 3 \\
\hline
\end{tabular}

mosquito populations. However, to the best of our knowledge, except the mosquito infestation reports, little is known about the behavior, ecology and genetics of $C$. anophelis. No data are available regarding the vector potentials for C. anophelis. Additionally, host preference of midges is one of the critical determinants of vector competence of midge-borne diseases $[11,12]$. The host preference is largely determined by blood source identification [12-17]. It might be a potential issue for midge blood meal analysis in the circumstances when C. anophelis specimens are present in a midge collection if specimens are not carefully identified, because the blood source of $C$. anophelis would be derived from the animals that mosquitoes feed on. The significant lack of knowledge about $C$. anophelis definitely warrants further investigations to increase the understanding of the midge.

\section{Ethical approval}

The study was carried out with the full approval of cow keepers and sampling was undertaken with approval of Yanfeng County, Haikou City, Hainan Province, China.

\section{Additional file}

Additional file 1: A midge Culicoides anophelis is ingesting blood from an engorged mosquito Anopheles vague. 


\section{Competing interests}

The authors declare that they have no competing interests.

\section{Authors' contributions}

All authors made contribution to the collection of insects. YM, JX and ZY discussed the paper structure, and JX and YM wrote the manuscript. HS edited the video. All authors read and approved the final version of the manuscript.

\section{Acknowledgments}

We thank Professor Yixin Yu in Center for Disease Control and Prevention of PLA for his confirmation of identification of the midge Culicoides anophelis. YM was supported by a grant of National Natural Science Foundation of China-Yunnan Joint Fund (U0932604), JX was supported by a NIH grant (1SC2GM092789-01A1).

\section{Author details}

${ }^{1}$ Department of Tropical Infectious Diseases, Second Military Medical University, 800 Xiangyin Road, 200433 Shanghai, China. ${ }^{2}$ Department of Biology, New Mexico State University, PO Box 30001 MSC 3AF, 88003, NM Las Cruces, USA. ${ }^{3}$ Center for Disease Control and Prevention of P.L.A, 20 Dongdajie Road Fengtai District, 100071 Beijing, China. ${ }^{4}$ Center for Disease Control and Prevention of Haikou City, Haikou, Hainan, China. ${ }^{5}$ Center for Disease Control and Prevention of Hainan Province, Haikou, Hainan, China.

Received: 23 October 2013 Accepted: 11 November 2013

Published: 13 November 2013

\section{References}

1. Edwards FW: On some Malayan and other species of Culicoides, with a note on the genus Lasiohelea. Bull Entomol Res 1922, 13:161-167.

2. Laird M: A ceratopogonine midge (Culicoides anophelis Edwards, 1922) sucking engorged blood from a mosquito (Armigeres lacuum Edwards, 1922) at Palmalmal, New Britain. Trans \& Proc R Soc N Z 1947, 76(2):158-161.

3. Chu Fl: Four species of the genus Culicoides (Diptera: Heleidae) from Hainan island, south China. Acta Entomol Sin 1959, 9(2):161-165.

4. Chhilar JS, Chaudhry S: First report of a biting midge Culicoides anophelis parasitzing mosquito Anopheles stephensi from North-western India. J Exp Sci 2010, 1(12):3-6.

5. Reddy CVS, Hafeez M: Studies on certain aspects of prevalence of Culicoides species. Indian J Anim Sci 2008, 78(2):138-142.

6. McKeever S, Wright MD, Hagan DV: Mouthparts of females of four Culicoides species (Diptera: ceratopogonidae). Ann Entomol Soc Am 1988, 81(2):332-341

7. Sutcliffe JF, Deepan PD: Anatomy and function of the mouthparts of the biting midge, Culicoides sanguisuga (Diptera: ceratopogonidae). J Morphol 1988, 198(3):353-365.

8. Carpenter S, Groschup MH, Garros C, Felippe-Bauer ML, Purse BV: Culicoides biting midges, arboviruses and public health in Europe. Antiviral Res 2013, 100(1):102-113.

9. Mellor PS, Boorman J, Baylis M: Culicoides biting midges: their role as arbovirus vectors. Annu Rev Entomol 2000, 45:307-340.

10. Weaver SC, Reisen WK: Present and future arboviral threats. Antiviral Res 2010, 85(2):328-345.

11. Ninio C, Augot D, Delecolle JC, Dufour B, Depaquit J: Contribution to the knowledge of Culicoides (Diptera: ceratopogonidae) host preferences in France. Parasitol Res 2011, 108(3):657-663.

12. Viennet E, Garros C, Gardes L, Rakotoarivony I, Allene X, Lancelot R, Crochet D, Moulia C, Baldet T, Balenghien T: Host preferences of Palaearctic Culicoides biting midges: implications for transmission of orbiviruses. Med Vet Entomol 2013, 27(3):255-266.

13. Calvo JH, Berzal B, Calvete C, Miranda MA, Estrada R, Lucientes J: Host feeding patterns of Culicoides species (Diptera: Ceratopogonidae) within the Picos de Europa National Park in northern Spain. Bull Entomol Res 2012, 102(6):692-697.

14. Lassen SB, Nielsen SA, Kristensen M: Identity and diversity of blood meal hosts of biting midges (Diptera: ceratopogonidae: Culicoides latreille) in Denmark. Parasite Vector 2012, 5:143.
15. Lassen SB, Nielsen SA, Skovgard H, Kristensen M: Molecular identification of bloodmeals from biting midges (Diptera: ceratopogonidae: Culicoides latreille) in Denmark. Parasitol Res 2011, 108(4):823-829.

16. Pettersson E, Bensch S, Ander M, Chirico J, Sigvald R, Ignell R: Molecular identification of bloodmeals and species composition in Culicoides biting midges. Med Vet Entomol 2013, 27(1):104-112.

17. Braverman Y, Frish K, Reis M, Mumcuoglu KY: Host Preference of Culicoides spp from Israel based on sensory organs and morphometry (Diptera: ceratopogonidae). Entomol Gen 2012, 34(1-2):97-110.

\section{doi:10.1186/1756-3305-6-326}

Cite this article as: Ma et al:: A video clip of the biting midge Culicoides anophelis ingesting blood from an engorged Anopheles mosquito in Hainan, China. Parasites \& Vectors 2013 6:326.

\section{Submit your next manuscript to BioMed Central and take full advantage of:}

- Convenient online submission

- Thorough peer review

- No space constraints or color figure charges

- Immediate publication on acceptance

- Inclusion in PubMed, CAS, Scopus and Google Scholar

- Research which is freely available for redistribution

Submit your manuscript at www.biomedcentral.com/submit
C Biomed Central 